\title{
Long-Term Effects of Treatment for Acute Lymphoblastic Leukemia with and without Cranial Irradiation on Growth and Puberty: A Comparative Study
}

\author{
A. C. S. HOKKEN-KOELEGA, J. W. D. VAN DOORN, K. HÄHLEN, T. STIJNEN,
} S. M. P. F. DE MUINCK KEIZER-SCHRAMA, AND S. L. S. DROP

Department of Pediatrics, Division of Endocrinology and Oncology, Sophia Children's Hospital/Erasmus University, Rotterdam, The Netherlands [A.C.S.H.-K., J.W.D.D., K.H., S.M.P.F.M.K.-S., S.L.S.D.]; and Department of Epidemiology and Biostatistics, Erasmus University, Rotterdam, The Netherlands [T.S.]

\begin{abstract}
We investigated the comparative effect on long-term growth of CNS prophylactic treatment for acute lymphoblastic leukemia (ALL) with either $25-\mathrm{Gy}$ cranial irradiation or moderate-dose i.v. methotrexate. In 80 children with complete continuous first remission, data on growth and pubertal development were investigated up to 11 y from ALL diagnosis. Forty patients had 25-Gy cranial irradiation, 16 of them with high-risk factors and 24 without. Another 40 non-high-risk ALL patients had moderate-dose methotrexate. Chemotherapy lasted $3 \frac{1 / 4}{y}$ for high-risk ALL patients and $21 / 4 \mathrm{y}$ for those not at high risk. Pubertal development and final height were assessed separately for girls diagnosed before or after age 7 and for boys before or after age 9 . All patients had a similar decline in height SD score during the first 6 mo of treatment, which persisted in irradiated children only. The nonirradiated group had no further decline. Catch-up growth only started when chemotherapy ended for irradiated and nonirradiated patients alike. Five $y$ after cessation of treatment, changes in height SD score for nonirradiated children remained within the range for healthy children against a significant decline in height SD scores for irradiated children. Pubertal development in irradiated girls diagnosed before age 7 was within normal range, but their final height was disappointing due to a blunted growth spurt. In contrast, irradiated girls diagnosed later had a delayed onset of puberty but satisfactory final height. Comparable results were found in boys. In summary, 25-Gy cranial irradiation in the treatment of ALL causes long-term growth retardation, whereas moderate-dose i.v. methotrexate seems to have only a temporary effect on growth. (Pediatr Res 33: 577-582, 1993)
\end{abstract}

\section{Abbreviations}

ALL, acute lymphoblastic leukemia

HR, high-risk

NHR, non-high-risk

MTX, methotrexate

MDMTX, moderate-dose methotrexate

FH, final height

GH, growth hormone

GHD, growth hormone deficiency

Received July 13, 1992; accepted December 30, 1992.

Correspondence: Dr. A. C. S. Hokken-Koelega, Sophia Children's Hospital

P. O. Box 70029, 3000 LL Rotterdam, The Netherlands.

Supported by a grant from Novo Nordisk A/S, Denmark.
PHV, peak height velocity

CI, confidence interval

Growth retardation is a common finding in children successfully treated for ALL (1-4). Various factors have been cited as contributing to growth retardation, including the disease itself, infection, and poor nutrition, but both cranial irradiation and chemotherapy have been proposed as the main etiologic agents $(3,4)$. Cranial irradiation as CNS prophylaxis has improved the survival rate of ALL children. Apart from being implicated in growth retardation, however, this treatment has been shown to have long-term neuropsychologic sequelae $(5,6)$. Cranial irradiation was therefore excluded from the Dutch treatment protocol for NHR-ALL in February 1983, to be replaced by i.v. MDMTX. In NHR-ALL, this system of CNS prophylaxis has been shown to be more effective than 25-Gy cranial irradiation in achieving continuous remission $(7,8)$, but its long-term effect on growth is unknown.

We evaluated growth, pubertal onset, and growth spurt, as well as FH in ALL children up to $11 \mathrm{y}$ after initiation of treatment with or without cranial irradiation.

\section{PATIENTS AND METHODS}

Between 1978 and 1988, 118 children (66 boys, 52 girls) were treated for ALL at the Sophia Children's Hospital, Rotterdam, The Netherlands, according to one of three standard treatment protocols all holding to the principle of early prophylaxis against CNS leukemia and long-term maintenance chemotherapy. Chemotherapy for induction and maintenance always involved vincristine, prednisone or dexamethasone, L-asparaginase, 6mercaptopurine, and MTX. Height was measured by experienced staff at each hospital visit.

There were 31 cases of ALL with initial HR factors, defined as an initial white blood cell count $\geq 50.10^{\circ} / \mathrm{L}$ and/or presence of mediastinal mass. These children (group 1: 17 boys, 14 girls) had protocol HR (9), including 25-Gy cranial irradiation in 13 fractions plus five doses of intrathecal MTX delivered in $3 \mathrm{wk}$, and, subsequently, intrathecal MTX plus prednisolone once every $7 \mathrm{wk}$ for $1 \mathrm{yr}$; chemotherapy lasted $31 / 4 \mathrm{y}$. NHR-ALL was diagnosed in 87 children, in 40 cases before February 1983. These 40 children (group 2: 23 boys, 17 girls) had protocol V (10), including 25-Gy cranial irradiation in 13 fractions delivered in $3 \mathrm{wk}$ plus five doses of intrathecal MTX, and for them, chemotherapy lasted $21 / 4 \mathrm{y}$. The remaining 47 NHR-ALL patients (group 3: 26 boys, 21 girls) had protocol VI (11), not involving 
cranial irradiation. They had a 24-h i.v. infusion of MDMTX (2 $\mathrm{g} / \mathrm{m}^{2}$ ) in combination with intrathecal MTX in three onceweekly courses and, subsequently, intrathecal triple therapy (MTX, cytarabine, and prednisolone) once every $7 \mathrm{wk}$ for $1 \mathrm{y}$. Chemotherapy for this group also lasted $2^{1 / 4}$ y. Protocols V and VI were designed by the Dutch Childhood Leukemia Study Group. All protocols are summarized in Table 1 .

Of these $118 \mathrm{ALL}$ patients, 80 (16 in group 1, 24 in group 2, and 40 in group 3) met the criteria for long-term analysis of growth and pubertal development: 1 ) persistence of complete first remission for at least 2 y from cessation of treatment; 2) no signs of CNS disease or constitutional chromosomal abnormality; and 3) no signs of puberty at diagnosis.

Each growth chart was reviewed whereby the thrice-monthly measurements during treatment and once-yearly thereafter were selected for further analysis. Height SD scores were calculated based on Dutch reference values (12). Results were expressed as the cumulative changes in height SD scores. The onset of puberty was determined using Tanner's charts; for girls it was defined as breast stage 2 and for boys, genital stage 2 with a testicular volume of $4 \mathrm{~mL}$ (13). The records were incomplete for this early phase in boys; therefore, we used genital stage 3 and/or a testicular volume of $6 \mathrm{~mL}$, which had been duly noted in all cases, as the starting point for the pubertal growth spurt in boys. FH was defined as a 6-mo growth under $0.2 \mathrm{~cm} / \mathrm{y}$ and/or a bone age of $16 \mathrm{y}$ in girls and $18 \mathrm{y}$ in boys. Bone age was calculated according to Greulich and Pyle (14).

Growth was analyzed in several ways. First, we assessed the cumulative changes in height SD scores in all subjects per group from diagnosis until the end of followup or study period. Four patients with severe growth retardation appeared to have GHD; three in group 1 and one in group 2. They were treated with biosynthetic GH starting 9.0, 8.3, and 8.4 y (group 1) and 9.3 y (group 2) after diagnosis. The change in height SD scores at their last visit before $\mathrm{GH}$ therapy was adhered to for subsequent growth analysis. In the second growth analysis, we eliminated any effect of the onset of puberty by assessing the cumulative changes in height SD scores in strictly prepubertal children from diagnosis up to $5 \mathrm{y}$ from cessation of treatment. At the first sign of puberty, subjects were dropped from the analysis. The onset of various pubertal stages was analyzed by applying life-table methods, taking into account the children who had not yet reached puberty at the end of the study period. ALL treatment may have interfered with the onset of various pubertal stages in girls older than 7 and boys older than $9 y$ at diagnosis. For this reason, we divided the children into subsets according to age at diagnosis. Pubertal development was thus regarded separately for girls diagnosed before or after the age of $7 \mathrm{y}$ and for boys before or after age 9 . The objective of the last analysis was to assess $\mathrm{FH}$ in relation to the onset of pubertal growth. For girls that had reached age 16 and boys that had reached age 18 before the end of the study period, we assessed the individual cumulative changes in height SD scores from diagnosis, at the end of treatment, at onset of pubertal growth, and for $\mathrm{FH}$, respectively. For reasons explained above, this assessment was also regarded separately for girls diagnosed before or after the age of 7 and for boys before age $9 \mathrm{y}$. For statistical evaluation of differences between the three groups regarding cumulative changes in height SD scores, we used one-way analysis of variance for selected points in time. If results were significant, this was followed by pairwise $t$ tests. Lifetable methods were applied for statistical analysis of the onset of various puberty stages. In the analysis of the two variables, age at start of puberty and age at menarche, the time variable was age itself. The children were counted at risk from the age at diagnosis until the start of puberty or menarche, or the end of the observation period, in which case the observation was considered to be censored. The distributions were estimated by Kaplan-Meier cumulative incidence curves (15). Differences between curves were assessed with the log-rank test.

\section{RESULTS}

The mean age at diagnosis for all 80 study patients was $4.8 \mathrm{y}$ (range, 0.8 to $14.0 \mathrm{y}$ ). Table 2 lists these patients per group in relation to the entire population.

Growth. At diagnosis, mean height SD scores did not differ from the norm for healthy Dutch children, nor was there a significant difference between groups; the difference amounted to -0.27 for group $1,0.03$ for group 2 , and 0.01 for group 3 . Figure 1 shows the cumulative changes in height SD scores per group for all study patients from diagnosis until the end of the study period. During the first 6 mo after diagnosis, all groups showed a significant decline in height compared with healthy children $(p<0.0001)$, with a mean change in height SD scores of -0.38 for group $1,-0.32$ for group 2 , and -0.26 for group 3 . During the remaining treatment period, the decline in height SD scores continued in the irradiated patient groups, whereas the nonirradiated patients had a very slight reversal with a mean change in height SD scores amounting to +0.09 for the remainder of the treatment. Consequently, the decline in height SD scores for the entire treatment period showed a significant difference between nonirradiated and irradiated patients, amounting to -0.17 in group 3 versus $-0.44(p<0.05)$ in group 2 and -1.02 $(p<0.005)$ in group 1 at the end of treatment.

During the first year after cessation of treatment, all groups showed a similar catchup growth. The increase in mean height SD scores amounted to +0.37 for group $1,+0.28$ for group 2, and +0.25 for group 3 , resulting in complete compensation for the preceding decline in height SD scores in group 3 (nonirradiated) only. From the second y after the end of treatment, height $\mathrm{SD}$ scores again began to decline significantly in the groups of irradiated children.

Five $y$ after the end of treatment, the change in height SD scores from diagnosis amounted to -0.89 for group 1 and -0.51 for group 2 , differing significantly from the change of -0.06 for group $3(p<0.005$ and $p<0.05$ for groups 1 and 2, respectively, $v S$ group 3 ). Thus, growth for the nonirradiated children remained within the normal range for healthy children. Subsequent growth data for this group were not available at the time of writing, as these children were diagnosed after February 1983.

Table 1. Treatment protocols for three groups of patients with $A L L^{*}$

\begin{tabular}{|c|c|c|c|c|c|c|c|c|c|c|c|c|c|}
\hline \multirow[b]{2}{*}{ Protocol } & \multirow[b]{2}{*}{ Group } & \multirow[b]{2}{*}{$\begin{array}{l}\text { Type } \\
\text { ALL }\end{array}$} & \multicolumn{3}{|c|}{ Induction $\dagger$} & \multicolumn{2}{|c|}{ CNS prophylaxis $\dagger$} & \multicolumn{6}{|c|}{ Maintenance } \\
\hline & & & $\begin{array}{l}\text { VCR, } \\
\text { Pred, } \\
\text { L-asp }\end{array}$ & DNR & $\begin{array}{l}\text { VCR, } \\
\text { Dexa, } \\
\text { L-asp }\end{array}$ & $\begin{array}{l}\text { XRT, } \\
\text { MTX it }\end{array}$ & $\begin{array}{c}\text { MDMTX, } \\
\text { MTX it }\end{array}$ & $\begin{array}{l}\text { VCR, } \\
\text { Pred }\end{array}$ & $\begin{array}{l}\text { VCR, } \\
\text { Dexa }\end{array}$ & $\begin{array}{l}\text { MTX, } \\
\text { 6-MP }\end{array}$ & CYC & $\begin{array}{l}\text { MTX it, } \\
\text { Pred it }\end{array}$ & $\begin{array}{l}\text { MTX it, } \\
\text { Pred it, } \\
\text { Ara-C it }\end{array}$ \\
\hline HR & 1 & HR & + & - & - & + & - & + & - & + & + & + & - \\
\hline V & 2 & NHR & + & \pm & - & + & - & + & - & + & - & - & - \\
\hline VI & 3 & NHR & - & - & + & - & + & - & + & + & - & - & + \\
\hline
\end{tabular}

* VCR, vincristine; Pred, prednisone orally; Pred it, prednisolone intrathecally; DNR, daunorubicine; Dexa, dexamethasone; L-asp, L-asparaginase;

XRT, 25-Gy cranial irradiation; it, intrathecally; 6-MP, 6-mercaptopurine; CYC, cyclophosphamide; Ara-C, cytarubine.

$\dagger$ Induction plus CNS prophylaxis lasted $3 \mathrm{mo}$

$+\operatorname{MDMTX}=2 \mathrm{~g} / \mathrm{m}^{2} / 24$ h i.v. MTX 
Table 2. Study patients in relation to entire ALL population 1978-1988

\begin{tabular}{|c|c|c|c|c|c|c|c|}
\hline \multirow[b]{2}{*}{ Group } & \multirow[b]{2}{*}{ Type ALL } & \multirow[b]{2}{*}{ Total } & \multicolumn{2}{|c|}{$\begin{array}{l}\text { Relapse in en- } \\
\text { tire population }\end{array}$} & \multicolumn{3}{|c|}{ Study patients } \\
\hline & & & $n$ & $\%$ & $\begin{array}{c}\text { Total } \\
(n)\end{array}$ & $\begin{array}{c}\text { Male/female } \\
(n)\end{array}$ & $\begin{array}{l}\text { Age at onset } \\
(y)^{*}\end{array}$ \\
\hline 1 & $\mathrm{HR}$ & 31 & 14 & 45 & 16 & $10 / 6$ & $5.2(2.1-13.0)$ \\
\hline 2 & NHR & 40 & 14 & 35 & 24 & $14 / 10$ & $4.9(0.8-14.0)$ \\
\hline 3 & NHR & 47 & 5 & 10.5 & 40 & $22 / 18$ & $4.7(1.5-12.4)$ \\
\hline Total & & 118 & 33 & & 80 & $46 / 34$ & $4.8(0.8-14.0)$ \\
\hline
\end{tabular}

* Values are mean (range).

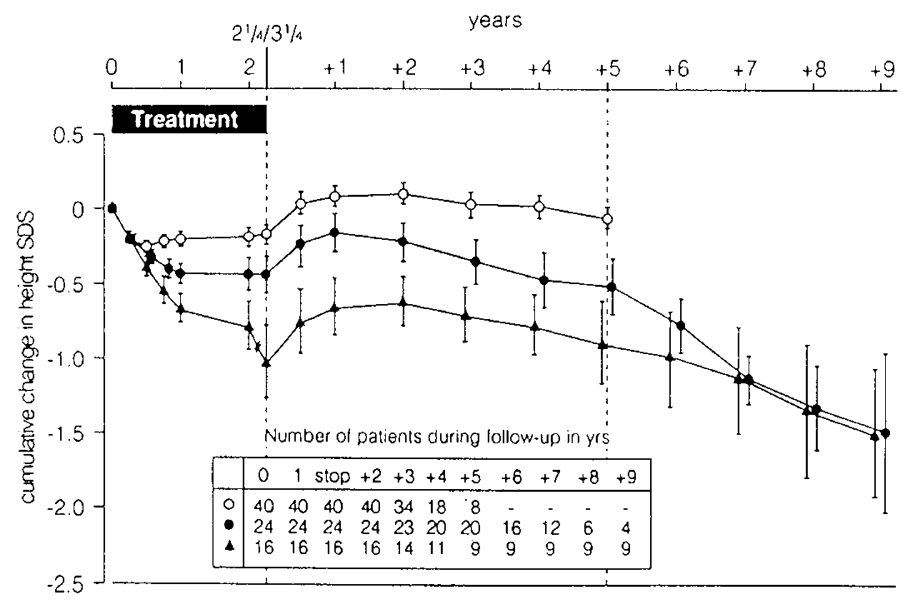

Fig. 1. Cumulative changes in height SD scores $(S D S)$ in 80 children up to 11 y of age from ALL diagnosis.

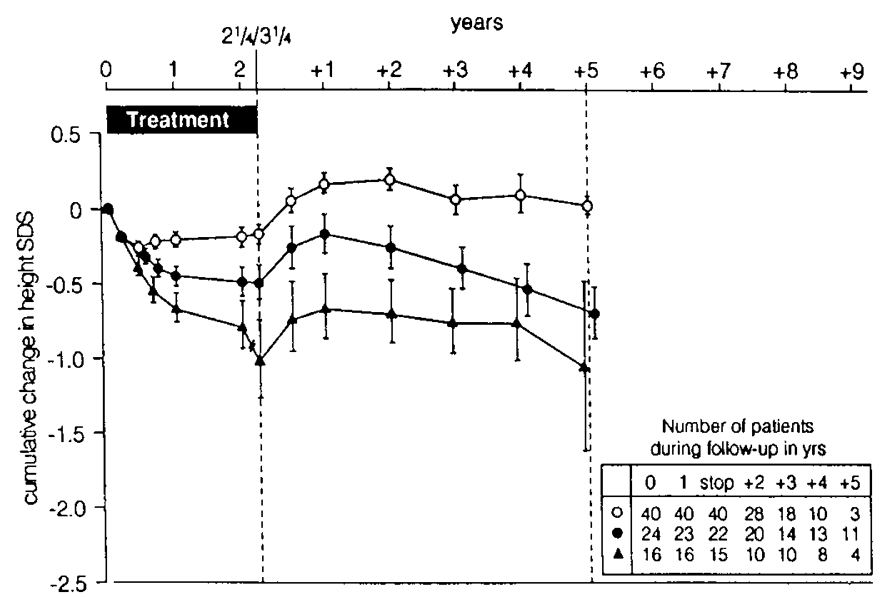

Fig. 2. Cumulative changes in height SD scores $(S D S)$ after ALL diagnosis in children remaining prepubertal up to $5 \mathrm{y}$ after end of treatment. $O$, group 3: nonirradiated NHR-ALL patients; $\bullet$, group 2: cranially irradiated (25 Gy) NHR-ALL patients; $\boldsymbol{\Lambda}$, group 1: cranially irradiated (25 Gy) HR-ALL patients.

As for the other two irradiated groups, 9 y after the end of treatment, the mean decline in height SD scores from diagnosis was -1.52 for group 1 and -1.48 for group 2 .

For all groups, the changes in height SD scores observed 2, 5, or $7 \mathrm{y}$ after diagnosis bore no relation to age or height at diagnosis. There was no correlation between the change in height SD scores for groups 1 and 2 during ALL treatment and that observed from the second year after treatment until the end of the study period.

Figure 2 gives the cumulative changes in height SD scores in strictly prepubertal children. The growth curves during treatment and for $5 \mathrm{y}$ after its cessation were not different from the curves for the same period in the general growth analysis (Fig. 1) that took no account of the onset of puberty.
Onset of puberty. Of 34 girls under study, 16 entered puberty before the end of the study period, nine (seven irradiated) belonging to the subset of 27 girls diagnosed before the age of $7 \mathrm{y}$ and seven (five irradiated) involving the entire subset diagnosed after age 7 . Life-table analysis revealed that puberty started at a median age of 10.7 y $(95 \% \mathrm{CI}$ : 9.5-11.6) in the irradiated girls diagnosed before age 7, similar to the norm for healthy Dutch girls (median age $10.5 \mathrm{y}$ ) (12). The median age for menarche in this group appeared to be 12.6 y (95\% CI: $11.1-13.9)$, which is only slightly earlier than the normal age (median 13.3).

The five irradiated girls diagnosed after age 7 started puberty at a median age of 12.5 y (95\% CI: $10.8-15.0)$ and had menarche at a median age of 14.0 y (95\% CI: $12.0-15.7)$, in both cases significantly later than in the girls diagnosed before the age of 7 $(p=0.007)$.

Of 46 boys under study, 17 entered puberty, 15 (12 irradiated) of whom had been under 9 y of age at diagnosis. Life-table analysis revealed that pubertal stage 3 and/or a testicular volume of $6 \mathrm{~mL}$ in irradiated boys was achieved at a median age of 12.7 y $(95 \%$ CI: 11.9-13.0). This is comparable to the norm for healthy Dutch boys (median age 13.0 y) (12). The remaining two boys were the only two boys diagnosed after age 9 . Both received irradiation, and their pubertal growth spurts started at 14.7 and $15.2 \mathrm{y}$. The limited number did not allow for life-table analysis as with the limited number of nonirradiated boys and girls that entered puberty.

Pubertal growth and FH. Figure 3 and Table 3 give the individual results for nine girls, seven of them irradiated, who were at least $16 \mathrm{y}$ old by the end of the study period. All had reached $\mathrm{FH}$. The mean $\mathrm{FH}$ for three irradiated girls, who were diagnosed before the age of 7 , was $156.3 \mathrm{~cm}$ (range, 153.0158.1 ), falling $12.5 \mathrm{~cm}$ below their mean target height. The mean PHV in these girls during their pubertal year of maximum growth was $6.8 \mathrm{~cm}$, which lies significantly below the normal expectation of $8.4 \mathrm{~cm}(p=0.01)(16)$. The mean change in height SD score from diagnosis was -0.64 at the onset of puberty (range, -1.13 to 0.25 ), with a subsequent pubertal decline in height SD score

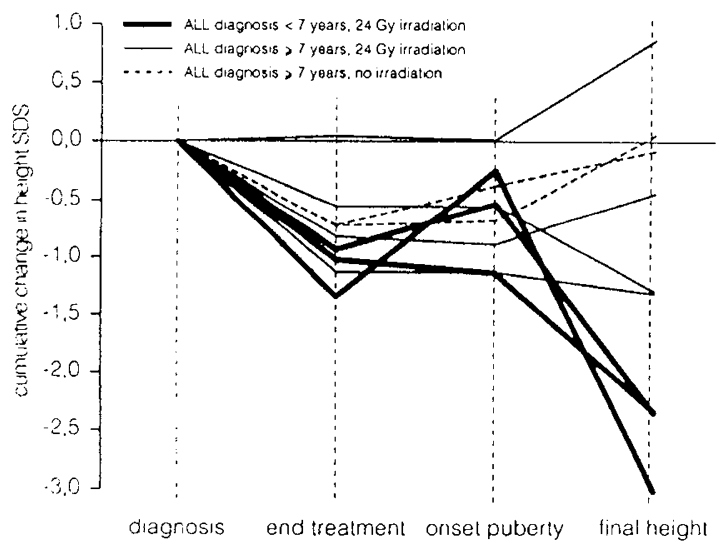

Fig. 3. Individual cumulative changes in heights SD scores $(S D S)$ in girls aged $\geq 16$ y at end of study period, diagnosed before or after age $7 \mathrm{y}$. 
Table 3. Individual data of girls and boys over age 16 and 18 , respectively, at the end of followup, divided according to age at diagnosis (division at 7 and $9 y$ )

\begin{tabular}{|c|c|c|c|c|c|c|c|c|c|}
\hline \multirow[b]{2}{*}{$\begin{array}{c}\text { Case } \\
\text { no. }\end{array}$} & \multirow[b]{2}{*}{ Sex } & \multirow{2}{*}{$\begin{array}{l}\text { Cranial } \\
\text { irradiation } \\
(25 \mathrm{~Gy})\end{array}$} & \multicolumn{3}{|c|}{ Age (y) } & \multicolumn{3}{|c|}{ Height SD score } & \multirow[b]{2}{*}{$\mathrm{FH}(\mathrm{cm})$} \\
\hline & & & $\begin{array}{c}\text { Diagnosis } \\
\text { of ALL }\end{array}$ & $\begin{array}{l}\text { Onset of } \\
\text { puberty* }\end{array}$ & Menarche & $\begin{array}{c}\text { End of ALL } \\
\text { treatment }\end{array}$ & $\begin{array}{l}\text { Onset of } \\
\text { puberty }\end{array}$ & $\mathrm{FH} \dagger$ & \\
\hline 1 & $\mathrm{~F}$ & + & 3.7 & 10.7 & 12.3 & -0.93 & -0.53 & -2.31 & 158.1 \\
\hline 2 & $\mathrm{~F}$ & + & 4.5 & 10.8 & 12.9 & -1.02 & -1.13 & -2.33 & 153.0 \\
\hline 3 & $\mathrm{~F}$ & + & 6.9 & 10.0 & 11.1 & -1.33 & -0.25 & -3.01 & 157.7 \\
\hline 4 & $\mathrm{~F}$ & + & 9.0 & 12.4 & 14.1 & -0.82 & -0.88 & -0.44 & 165.0 \\
\hline 5 & $\mathrm{~F}$ & + & 10.0 & 15.0 & 16.3 & +0.04 & +0.01 & +0.86 & 173.6 \\
\hline 6 & $\mathrm{~F}$ & + & 10.2 & 10.7 & 12.2 & -0.55 & -0.55 & -1.28 & 156.7 \\
\hline 7 & $\mathrm{~F}$ & + & 14.0 & 12.5 & 14.0 & -1.12 & -1.12 & -1.30 & 169.0 \\
\hline 8 & $\mathrm{~F}$ & - & 9.3 & 12.2 & 14.3 & -0.72 & -0.38 & -0.08 & 166.0 \\
\hline 9 & $\mathrm{~F}$ & - & 10.3 & 12.6 & 13.9 & -0.73 & -0.68 & +0.05 & 166.2 \\
\hline 10 & M & + & 4.7 & 12.5 & & -1.13 & -0.66 & -0.98 & 165.5 \\
\hline 11 & M & + & 4.8 & 13.0 & & -0.47 & -0.30 & -1.34 & 169.0 \\
\hline 12 & $\mathrm{M}$ & + & 8.7 & 14.1 & & -0.67 & -0.72 & -0.70 & 171.9 \\
\hline 13 & M & + & 8.8 & 14.0 & & -0.70 & -0.41 & -0.55 & 168.0 \\
\hline
\end{tabular}

* In boys, genital stage 3 and/or testicular volume of $6 \mathrm{~mL}$.

$\dagger \geq 16$ y for girls, $\geq 18$ y for boys.

of -1.91 until FH (range, -2.76 to -1.20 ) was reached. In contrast, the other four irradiated girls, who were all diagnosed after the age of 7 (range, $9.0-14.0 \mathrm{y}$ ), reached a mean $\mathrm{FH}$ of $165.9 \mathrm{~cm}$ (range, 156.7-173.6), falling only $3.2 \mathrm{~cm}$ below their mean target height. In these girls, the catchup growth after cessation of ALL therapy interfered with PHV. Their mean pubertal change in height SD score was +0.1 (range, -0.73 to +0.85 ). Comparing the results for irradiated girls diagnosed before the age of $7 \mathrm{y}$ with those diagnosed after $7 \mathrm{y}$, there was a significant difference in $\mathrm{FH}$ and the divergence between $\mathrm{FH}$ and target height ( $p=0.007$ and $p=0.02$, respectively). For the two nonirradiated girls, both over 7 y old at diagnosis, the $\mathrm{FH}$ amounted to 166.0 and $166.2 \mathrm{~cm}$, differing from target height by 0 and $-4.4 \mathrm{~cm}$.

Four boys had turned 18 y of age before the end of the study period. They had achieved $\mathrm{FH}$ and were all diagnosed before the age of $9 \mathrm{y}$, and all underwent cranial irradiation. Individual results are shown in Figure 4 and Table 3. Mean FH was 168.6 $\mathrm{cm}$ (range, 165.5-171.9), falling $10.3 \mathrm{~cm}$ below their target height (range, 6.1-13.3). Mean PHV was $8.4 \mathrm{~cm}$, which lies below the mean PHV of $9.5 \mathrm{~cm}$ for healthy boys $(p=0.06)(16)$. Mean change in height SD scores from diagnosis was -0.74 (range, -1.13 to -0.47$)$ at the end of ALL therapy and $-0.52(-0.72$ to

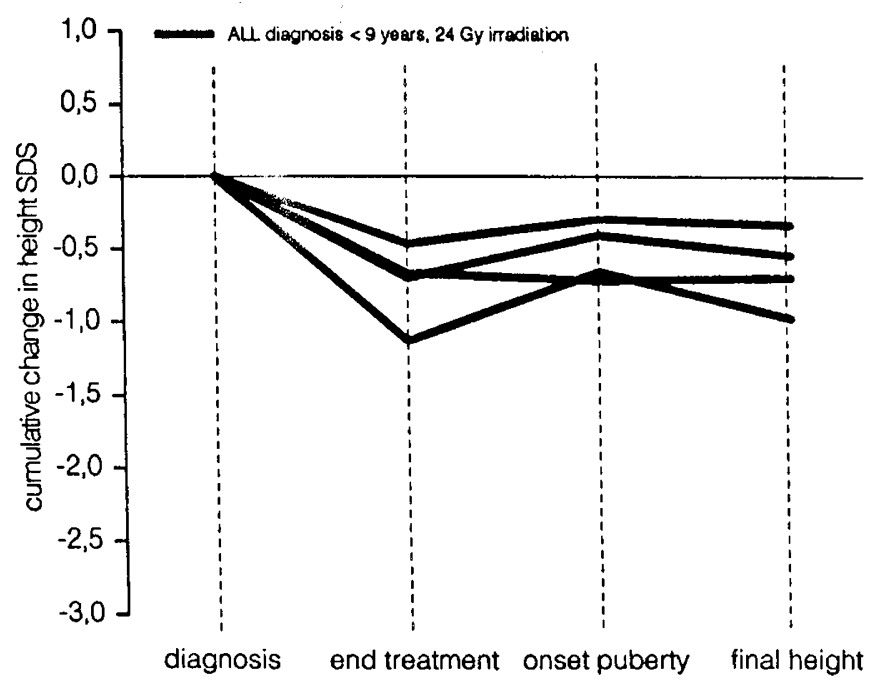

Fig. 4. Individual cumulative changes in height $\mathrm{SD}$ scores $(S D S)$ in irradiated boys aged $\geq 18 \mathrm{y}$ at end of study period, all diagnosed before age $9 \mathrm{y}$.
-0.30 ) at the onset of pubertal growth spurt, with a subsequent pubertal change in height SD scores of $-0.30(-1.04$ to +0.02$)$ up to FH. None of the boys with ALL diagnosed after age 9 had reached the age of 18 at the end of the study period.

\section{DISCUSSION}

All of our patients had a significant decline in height SD scores during the first 6 mo after diagnosis, confirming the findings of other investigators $(3,4,17-20)$. The absence of a difference between irradiated and nonirradiated children during the first 6 mo after diagnosis in our comparative study suggests that cranial irradiation does not play a major part in the initial decline in height SD scores. However, cranial irradiation does appear to be the main etiologic agent in continuous, long-term growth deceleration. After those first $6 \mathrm{mo}$, height SD scores continued to decline in the irradiated children only for the entire duration of chemotherapy, starting anew 2 y after the end of treatment. Five $y$ after the end of treatment, the height SD scores for both groups of irradiated children had declined significantly, whereas the mean change in height SD score for the nonirradiated group did not differ from the norm for healthy children. The growth analysis of strictly prepubertal children, from diagnosis until $5 \mathrm{y}$ after the end of therapy, showed the same significant difference between irradiated and nonirradiated children.

Chemotherapy does appear to influence growth to some extent, at least for the duration of its administration, as growth improved only marginally in the nonirradiated children while they were under treatment. We assume that this inhibition of catchup growth is mainly due to steroids. As soon as chemotherapy ceased, there was an immediate surge of catchup growth in irradiated and nonirradiated children alike.

Most growth studies in children with ALL who received 24or 25-Gy cranial irradiation have shown a significant decrease in linear growth during and after therapy (1-4). Radiation injury of the hypothalamic-pituitary axis with reduced $\mathrm{GH}$ secretion was revealed as main etiologic agent in this growth retardation $(18,21,22)$. None of those children showed hypothyroidism or impaired adrenal function $(3,23)$. We did not perform systematic studies of GH secretion. Several studies have emphasized the limited value of $\mathrm{GH}$ stimulation tests as the sole predictor of GHD $(24,25)$. Normal growth despite abnormalities of $\mathrm{GH}$ secretion, as well as normal GH secretion and low height velocity, have been found in children treated for $\operatorname{ALL}(3,26)$. Measurement of pulsatile $\mathrm{GH}$ secretion may be a more sensitive and reproducible indicator of $\mathrm{GH}$ abnormalities, especially in children who underwent cranial irradiation $(22,27)$. In our hospital, 
it is the policy to evaluate $\mathrm{GH}$ secretion in these children only when a persistently poor growth rate is found after completion of chemotherapy and height has dropped below the 10th percentile (12), i.e. only in children for whom GH treatment is being considered. Only four of 40 irradiated children met those criteria and had biochemical evidence of GHD during a $\mathrm{GH}$ stimulation test or 24-h GH secretion. This does not preclude that several other children with a height above the 10th percentile, but showing growth retardation after ALL therapy, may have GHD as well.

Growth in ALL patients treated with CNS prophylaxis by means of i.v. MDMTX has been studied by others $(19,20)$. However, ours is the first comparative study of long-term growth after treatment for ALL, including CNS prophylaxis with either cranial irradiation or MDMTX. Our results show that complete compensation for the initial decline in height SD scores and normal growth thereafter can be achieved in nonirradiated children. These findings suggest that the long-term effect of MTX on growth can be only minimal. Thus, chemotherapy seems to have no deleterious effect on the hypothalamus and/or pituitary gland, but conclusive statements may be premature in view of the limited number of nonirradiated children in our study that have entered puberty.

Most growth studies in children with ALL concern growth before puberty, whereas reports about pubertal development as such or in relation to growth are limited and confined to girls only (28). Early and precocious puberty has been observed in girls after hypothalamic and pituitary irradiation with 24 to 40 Gy $(28-30)$. In contrast, our study showed a normal range regarding onset of puberty and menarche for girls diagnosed before age 7; the slightly younger age at menarche was not significant. Moreover, in girls who were at least age 7 at diagnosis, both onset of puberty and menarche occurred significantly later than in healthy girls. Those girls were undergoing treatment around the time that puberty normally starts, and chemotherapy may well have caused the delay. The divergence between our findings and those reported in the literature may be due to the fact that the other workers did not carry out life-table analyses, which may have biased their results.

In boys diagnosed before the age of $9 \mathrm{y}$, similarly, the age at which the pubertal growth spurt occurred was within normal limits. Because only two boys were diagnosed after age 9 , we cannot draw conclusions, even though they did have a delayed pubertal growth spurt.

There are no literature data on mean PHV during the pubertal growth spurt or FH in boys treated for ALL. Regarding girls, Moëll et al. (28) reported blunting of the pubertal growth spurt, possibly caused by a subnormal ability to respond to the increased demands on GH secretion. Our findings indicate that irradiated girls and boys diagnosed before age 7 and 9 , respectively, have lower mean PHV during puberty than healthy children, resulting in a disappointing $\mathrm{FH}$. Careful monitoring of these patients is essential in view of their blunted growth spurt and subnormal GH secretion during puberty. Treatment with GH might be considered for those children whose height at onset of puberty is such that short adult stature is to be expected. The final height of girls diagnosed after age $7 \mathrm{y}$ did not differ significantly from healthy girls. The divergence between the FH achievements in children diagnosed before or after the age of 7 in girls (or 9 in boys) appears not to be attributed to the early pubertal onset but may be the result of disturbances in $\mathrm{GH}$ secretion that have been developed during the longer followup period in patients with early diagnosis.

In summary, our results clearly show that cranial irradiation with $25 \mathrm{~Gy}$ is the main causative factor in growth retardation in children treated for ALL. In contrast, CNS prophylaxis with i.v. MDMTX has minimal long-term effect on linear growth. Chemotherapy has only a temporary effect on growth in that it inhibits catchup growth during its administration. In children that present with ALL at an early age, neither the disease nor its treatment, including 25-Gy cranial irradiation, seems to affect the onset of puberty, but FH will be disappointing. Conversely, at least in girls, late presentation of ALL followed by the same treatment will probably lead to a delay in the pubertal development, whereas FH will be satisfactory.

Acknowledgment. The authors thank M. A. J. de Ridder for statistical assistance, J. Drost-van den Linden for secretarial assistance, and A. Ribbink for editing the manuscript.

\section{REFERENCES}

1. Shalet SM, Beardwell CG, Morris PH, Pearson D 1976 Growth hormone deficiency after treatment of acute leukemia in children. Arch Dis Child 51:489-493

2. Robison LL, Nesbit ME, Sather HN, Meadows AT, Ortega JA, Hammond GD 1985 Height of children successfully treated for acute lymphoblastic leukemia: a report from the late effects study committee of Children's Cancer Study Group. Med Pediatr Oncol 13:14-21

3. Kirk JA, Raghupathy P, Stevens MM, Cowell CT, Menser MA, Bergin M, Tink A, Vines RH, Silkink M 1987 Growth failure and growth-hormone deficiency after treatment for acute lymphoblastic leukemia. Lancet 1:190193

4. Clayton PE, Shalet SM, Morris-Jones PH, Price DA 1988 Growth in children treated for acute lymphoblastic leukemia. Lancet 1:460-462

5. Eiser C 1978 Intellectual abilities among survivors of childhood leukemia as a function of CNS irradiation. Arch Dis Child 53:391-395

6. Williams JM, Davis KS 1986 Central nervous system prophylactic treatment for childhood leukemia: neuropsychological outcome studies. Cancer Treat Rev 13:1-15

7. Freeman AI, Weinberg M, Brecher ML, Jones D, Glicksman AS, Sinks LF, Weil M, Pleuss H, Hananian J, Burgert Jr EO, Gilchrist GS, Necheles T, Harris M, Kung F, Patterson RB, Maurer H, Leventhal B, Chevalier L, Forman E, Holland JF 1983 Comparison of intermediate-dose methotrexate with cranial irradiation for the post-induction treatment of acute lymphocytic leukemia in children. N Engl J Med 308:477-484

8. Abromowitch M, Ochs J, Pui CH 1988 High-dose methotrexate improves clinical outcome in children with acute lymphoblastic leukemia: St Jude total therapy study X. Med Pediatr Oncol 16:297-303

9. Hooykaas H, Hählen K, Adriaansen HJ, Dekker I, Van Zanen GE, Van Dongen JM 1989 Terminal deoxynucleotidyl transferase (TdT)-positive cells in cerebrospinal fluid and development of overt CNS leukemia: a 5-year follow-up study in 113 children with a TdT-positive leukemia or nonHodgkin's lymphoma. Blood 74:416-422

10. Van der Does-van den Berg A, Van Wering ER, Suciu S, Solbu G, Van 't Veer MB, Rammeloo JA, De Koning J, Van Zanen GE 1989 Effectiveness of rubidomycin in induction therapy with vincristine, prednisone, and L-asparaginase for standard risk childhood acute lymphoblastic leukemia: results of a Dutch phase III study (ALL V). Am J Pediatr Hematol Oncol 11:125133

11. Veerman AJP, Hählen K, Kamps WA, Van Leeuwen EF, De Vaan GAM, Van Wering ER, Van der Does-van den Berg A, Solbu G, Suciu S 1990 Dutch childhood leukemia study group: early results of study ALL VI (19841988). In: Buchner T, Schellong G, Hiddeman W, Ritter J (eds) Haematology and Blood Transfusion. Springer-Verlag, Berlin/Heidelberg, pp 473-476

12. Roede MJ, van Wieringen JC 1985 Growth diagrams 1980 . Netherlands third nation-wide biometric survey. Tijdschr Soc Gezondheidszorg 63(Suppl): 134

13. Tanner JM, Whitehouse RH 1976 Longitudinal standards for height, weightheight, weight-velocity and stages of puberty. Arch Dis Child 51:170-179

14. Greulich W, Pyle I 1959 Radiographic atlas of skeletal development of the hand and wrist. Stanford University Press, Stanford, CA

15. Armitage P, Berry G 1987 Statistical Methods in Medical Research, 2nd ed. Blackwell Scientific Publications, London

16. Tanner JM, Whitehouse RH, Takaishi M 1966 Standards from birth to maturity for height, weight, height velocity and weight velocity: British children (1965). Arch Dis Child 41:613-635

17. Hakami N, Mohammad A, Meyer JW 1980 Growth and growth hormone of children with acute lymphocytic leukemia following central nervous system prophylaxis with and without cranial irradiation. Am J Pediatr Hematol Oncol 2:311-316

18. Wells R, Foster M, D'Ercole AJ, McMillan C 1983 The impact of cranial irradiation on the growth of children with acute lymphocytic leukemia. Am J Dis Child 137:37-39

19. Moëll C, Garwicz S, Marky I, Mellander L, Karlberg J 1988 Growth in children treated for acute lymphoblastic leukemia with and without prophylactic cranial irradiation. Acta Paediatr Scand 77:688-692

20. Katz JA, Chambers B, Everhart C, Marks JF, Buchanan GR 1991 Linear growth in children with acute lymphoblastic leukemia without cranial irradiation. J Pediatr 1 18:575-578

21. Starceski PJ, Lee PA, Blatt J, Finegold D, Brown D 1987 Comparable effects of 1800- and 2400-rad (18- and 24-Gy) cranial irradiation on height and weight in children treated for acute lymphoblastic leukemia. Am J Dis Child 141:550-552

22. Blatt J, Bercu BB, Gillin J, Mendelson WB, Poplack DG 1984 Reduced 
pulsatile growth hormone secretion in children after therapy for acute lymphoblastic leukemia. J Pediatr 104:182-186

23. Shalet SM, Beardwell CG, Twomey JA, Morris Jones PH, Pearson D 1977 Endocrine function following the treatment of acute leukemia in childhood J Pediatr 90:920-923

24. Brook CGD, Hindmarsh PC 1991 Tests for growth hormone secretion. Arch Dis Child 66:85-87

25. Caccani E, Taasoni P, Parisi G, Pirazzoli P, Zucchini S, Mandini M, Cicognani A, Balsamo A 1992 Pitfalls in diagnosing impaired growth hormone $(\mathrm{GH})$ secretion: retesting after replacement therapy of 63 patients defined as $\mathrm{GH}$ deficient. J Clin Endocrinol Metab 74:1284-1289

26. Shalet SM, Price DA, Beardwell CG, Morris Jones PH, Pearson D 1979 Normal growth despite abnormalities of growth hormone secretion in children treated for acute leukemia. J Pediatr 94:719-722
27. Zadik Z, Chalew SA, Gilula Z, Kowarski AA 1990 Reproducibility of growth hormone testing procedures: a comparison between 24-hour integrated concentration and pharmacological stimulation. J Clin Endocrinol Metab 71:1127-1130

28. Moëll C 1988 Disturbed pubertal growth in girls after acute leukemia: a relative growth hormone insufficiency with late presentation. Acta Paediatr Scand [Suppl] 343:162-166

29. Leiper AD, Stanhope R, Kitching P, Chessels JM 1987 Precocious and premature puberty associated with treatment of acute lymphoblastic leukemia Arch Dis Child 62:1107-1112

30. Otten BJ, Lippens RJJ, van 't Hof MA 1988 Growth and puberty in children with acute lymphoblastic leukemia. Acta Paediatr Scand [Suppl] 343:224225

\section{Announcement}

\section{American Board of Nutrition 1993 Examination}

In response to a high level of interest, the deadline for receipt of application, academic records, and sponsoring letters has been extended to July 1,1993 .

The next certifying examination of the American Board of Nutrition will be administered in Milwaukee, WI on the morning of Friday, October 15, 1993, before the Postgraduate Course jointly sponsored by ASCN, NAASO, and ADA.

Individuals with a doctoral degree (M.D. Ph.D., or equivalent) and an appropriate nutrition background are eligible to take the examination. M.D. candidates must be certified by a primary board recognized by the American Board of Medical Specialties and must have completed at least 2 years of appropriate nutrition training at the time of the examination, including 1 year of clinical experience. Ph.D. candidates must have at least 2 years of postdoctoral experience in human nutrition. In a new 4-hour format, there will be two written phases of the examination. Phase I will test broad knowledge of the fundamentals of nutrition, and Phase II will test the clinical applications of the knowledge.

For more detailed information, write or call: The American Board of Nutrition, 9650 Rockville Pike, Bethesda, MD 20814, (301) 530-7111. 